\title{
Low Cost Interactive board using Infrared Pen and Wiimote
}

\author{
C. Photong, A. Polyiam, K. Phomsathet \\ Solar Energy and Energy Resources Research Unit, Faculty \\ ofEngineering \\ Mahasarakham University \\ Thailand
}

\begin{abstract}
Interactive boards are usually used for the smart classrooms where both teachers and students can learn the lessons interactively through the boards. However, the current prices of these boards are relatively high; 4,500-7,000 USD. This paper proposes an alternatively low cost interactive board usingan infrared pen and a Wiimote. The proposed board consists of an infrared pen, a Wiimote, a projector, a computer and a display screen. The infrared pen createsan infrared spoton the display screen when pressed, whichthen will be detected by the Wiimote. The Wiimote sends the position of the spot on the screen to the computer installed the Wiimote program. Then, the computer converts the infrared spot into a drawing spot as does the regular pen with desired colour while the resultant spot is shown on the screen via the regular projector. The proposed interactive board has an approximately price up to 2,500 USD, which is1.8-2.8 times less expensive compared with the commercial boards.
\end{abstract}

Keywords-interactive boards; low cost boards; smart classrooms; infrared pens; wiimote

\section{INTRODUCTION}

Using regular blackboards or whiteboards with chalks or whiteboard pens may cause some health problems due to dusts or chemical substances.To avoid these problems, many teachers may use a computer with a projector instead. However,teachers may have some inconvenient since they have to stay in front of the computerat most time for control the display during the classes. An interactive board would be an alternative choice since it allows both teachers and students to control the display directly at the board via a finger, pen or other device [1]-[5].Unfortunately, the prices of commercial interactive boards arerelativelyhigh (\$4,500-7,000 US) [6].

This paper proposes an alternative type of interactive boards using infrared pens and a Wiimote. Details of components and operation principle of the board are presented in Section 2. Details of the constructed board prototype and its experimental results and discussions are presented in Section 3; following by the conclusions in Section 4, respectively.

\section{COMPONENTS AND OPERATION PRINCIPLE}

Figure 1 shows the prototype of the proposed interactive board. The board consists of 5 components: a computer, a projector,an infrared pen(s), a Wiimote and a display screen, designated by the numbers 1, 2, 3, 4 and 5, respectively.

\author{
N. Suwapaet \\ Bio-Energy and Renewable Resources Research Unit, \\ Faculty of Engineering \\ Mahasarakham University \\ Thailand
}

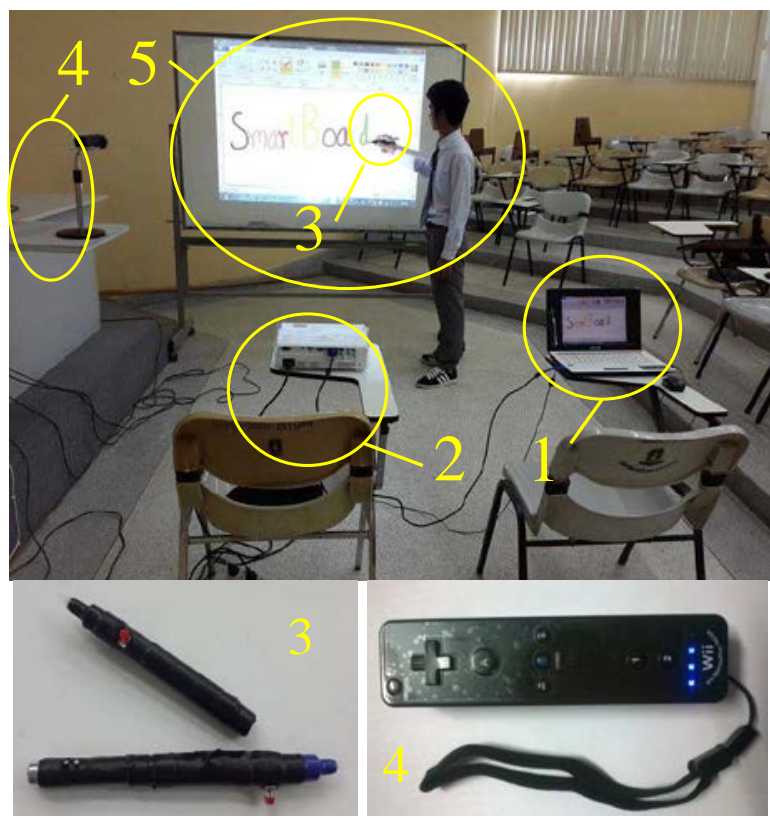

FIGURE I. COMPONENTS OF THE PROPOSED INTERACTIVE BOARD.

The proposed interactive board operates when the user presses the button on the infrared pen (3) for drawing or selecting/clicking the object on the display screen (5). This action thuscreates an infrared spot on the display screen (5) at the same time. The Wiimote (4) has a function to detect the infrared spot appearing on the screen real-time, while sending information of position of the spot on the screen to the computer (1) via bluetooth at the same time. The computer (1) then processes the calculation that converts the infrared spot into the graphical spot with desired color and size (the color and size of the graphical spot can be selected or changed by the user via a computer). The graphical spot then is sent to magnify the picture size as required by the projector (2) and from the projector to show on the display screen (5), respectively.By this way, the user can draw or select/click the object directly on the screen, as well as changing the spot/line's color and size independently, without sitting in front of the computer all the time. 


\section{EXPERIMENTAL RESULTS AND DISCUSSIONS}

The proposed interactive board was tested with the most often used programs for teaching classes, which were Microsoft PowerPoint, Microsoft Word and Paintbrush. Figure 2 shows the successive results of the tests. The proposed board can operate properly and effectively for all the tests.

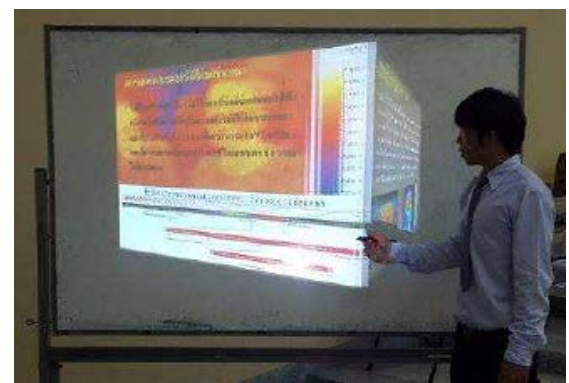

(a) Testing with MS PowerPoint

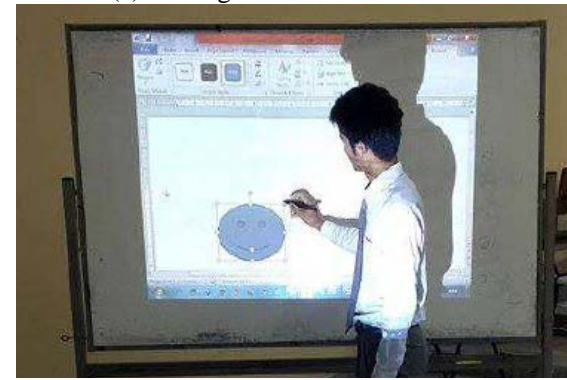

(b) Testing with MS Word

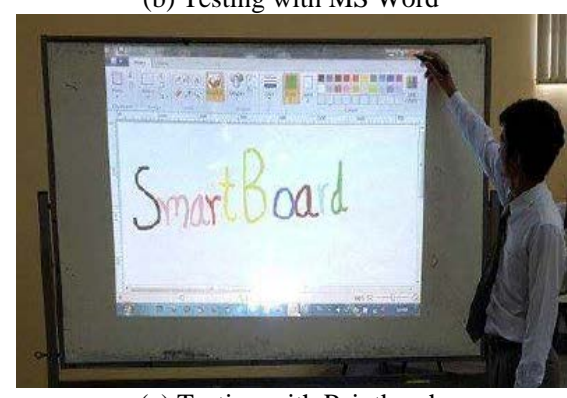

(c) Testing with Paintbrush

FIGURE II. EXPERIMENTAL RESULTS WHEN TESTING THE BOARD WITH PROGRAM MICROSOFT POWERPOINT, MICROSOFT WORD, MICROSOFT EXCEL AND PAINTBRUSH.

Figure 3 showsparametersl and $\theta$ on the proposed interactive board.These parameterswereused inthe experimental tests for investigating infrared spot detection performance of the Wiimote when installed the Wiimote with different distances and angles; wherel was defined as a distance between the Wiimote and central of the display screen and $\theta$ as a setting angle of the Wiimote compared to the normal line of the display screen. The Wiimote was assigned to detect 4 testing infrared spots locating at the center of each quadrant of the screen.The results from the tests are as shown in Figure 4.

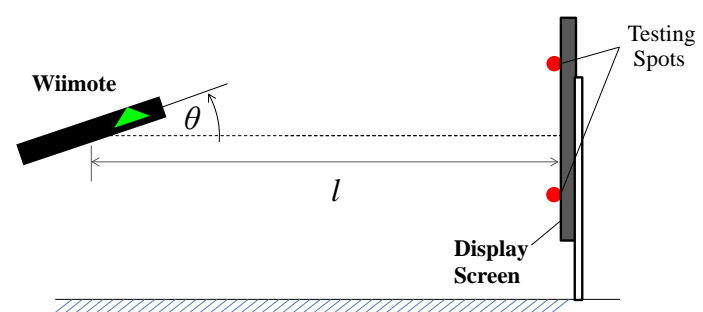

(a)Left-side view

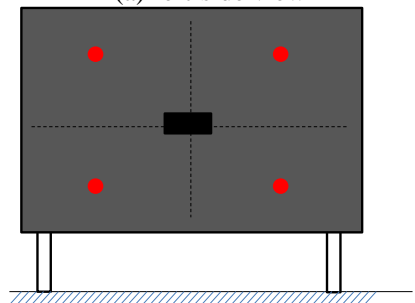

(b) Front view

FIGURE III. PARAMETERS USED FOR INVESTIGATING PERFORMANCE OF WIIMOTE.

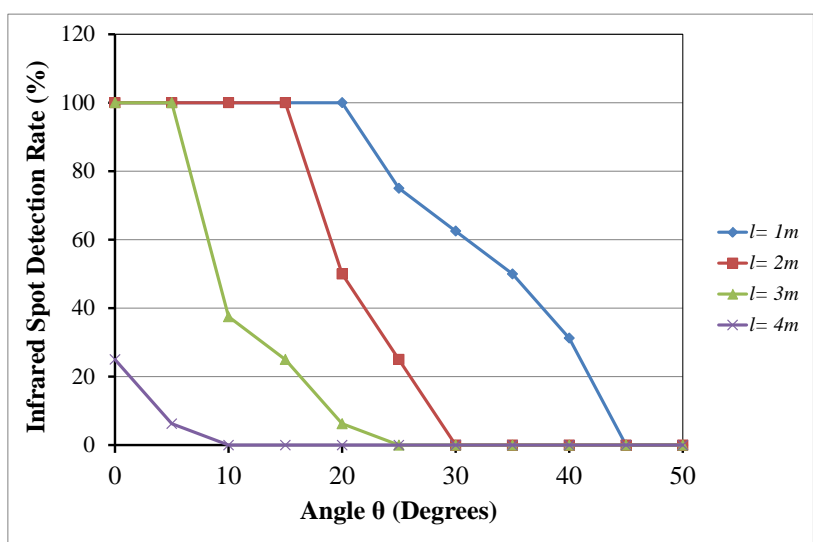

FIGURE IV.

EXPERIMENTAL RESULTS OBTAINED FROM DIFFERENT VALUES OF L AND $\Theta$.

It would be concluded from the test results shown in Figure 4 that the Wiimote will have better capability of infrared spot detection when it was installed closer to the screen with less value of $\theta$. For this prototype, the Wiimote could detect all spots with the installed distance up to 3 meters from the screen and with the angle of $\theta$ less than 5 degrees. The higher degrees of $\theta$ would be allowable only for the shorter installation distances of $l$, but would not be greater than 25 degrees at installed distance of 1 meter. These results reflect to the limitation when designing or implementing the Wiimote for the application such the interactive board. The proper distance and suitable angle for setting the Wiimote must be considered; otherwise, improved version of the Wiimote with higher detection rate at longer distance should be used instead.

\section{CONCLUSIONS}

An alternative type of the interactive board using infrared pen and Wiimote has been proposed in this paper. The proposed interactive board can achieve $1.8-2.8$ times lower cost compared with the other commercial interactive boards. The proposed board prototype can operate properly with often used programs such as Microsoft PowerPoint, Microsoft Word and Paintbrush.It should be noted that the distance and angle 
between the Wiimote and the display screen of the board should beselected properly in order to achieve lowest errors for the displays.

\section{ACKNOWLEDGEMENT}

Authors would like to thank the General Education, Mahasarakham University, Thailand, forthe funding for this research with the research budget, year 2014.

\section{REFERENCES}

[1] Gage, J., How to Use an Interactive Whiteboard Really Effectively in Your Primary Classroom, Taylor \& Francis eBooks, 2004.

[2] Heather, J. S., Steve H., Kate, W., Jen, M., Interactive whiteboards: boon or bandwagon?A critical review of the literature, Journal of Computer Assisted Learning, Vol. 21, Issue 2, pp: 91-101, 2005.

[3] Victoria, A., Sally, B., Rosamund, S., Sarah, C., Simon, M. and Ian, T., Collaborative research methodology for investigating teaching and learning: the use of interactive whiteboard technology, Educational Review, Vol. 57, Issue 4, pp: 457-469, 2005.

[4] Nabeel, A., Determinants of interactive white board success in teaching in higher education institutions Original Research Article, Computers \& Education, Vol. 56, Issue 3, pp: 827-838, 2011.

[5] Essam, B., Mohammed, J. S. A., Teachers' Perceptions Regarding the Benefits of using the Interactive Whiteboard (IWB): The Case of a Saudi Intermediate School Original Research Article Procedia, Social and Behavioral Sciences, Vol. 64, pp: 179-185, 2012.

[6] TechLearn, Interactive Whiteboards in Education, http://www.jisc.ac.uk/. 